\title{
Estenosis Bronquial por cuerpo extraño. Tratamiento Quirúrgico en el niño de 5 años.
}

\author{
Dr. Alberto Gyhra S., Dr. Claudio Santander K., Dr. Daniel Acuña B., \\ Dr. Octavio Enríquez L., Dr. Jacob Israel M. ${ }^{1}$ \\ Bronchial Stenosis at five years of age.
}

\begin{abstract}
The case of a five years old girl with stenosis of the left main bronchus; 1 crn. below the carina, secondary to foreing body (bean), is presented. Surgical repair and successful results thirty month later, are described.
\end{abstract}

Las estenosis bronquiales orgánicas, pueden ser congénitas o adquiridas; del grupo de las adquiridas las causas más frecuentes son: (1) Extrabronquiales (Adenopatías, Neoplasias, Aneurismas, Agrandamiento cavidades cardíacas, etc.) (2) Endobronquiales (Cuerpo extraño, Broncolitiasis, etc.). (3) Parietales (Alteraciones circulatorias por estasis y edema de la mucosa bronquial, TubercuJosis, Neoplasias benignas y malignas, acción de sustancjas cáusticas y cicatrización de procesos traumáticos.

La estenosis bronquial es un cuadro clínico poco frecuente; presentamos el caso de una estenosis en el bronquio izquierdo a $1 \mathrm{~cm}$. de la carina debido a la impactación de un cuerpo extraño (poroto) durante 20 dias.

\section{HISTORIA CLINICA}

Niña de 5 años de edad, con antecedentes de haber sido sometida hace 11 meses a traqueostomía, broncoscopía y extirpación de cuerpo extraño (poroto) alojado 20 días en el bronquio izquier. do. El protocolo relata que fue un procedimiento dificil, logrando extirpar el poroto en varios trozos, describiéndose la mucosa bronquial edematosa y congestiva.

Consulta por tos irritativa, estridor y dificultad respiratoria progresiva, el examen torácico mostró disminución de las vibraciones vocales e hipersonoridad en la base izquierda; la radiografía simple

1 Departamento de Cirugía, Facultad de Medicina, Universidad de Concepción - Servicio de Cirugía Hospital Guillermo Grant Benavente, Concepción. de tórax muestra hipertransparencia del hemitórax izquierdo. Se practica una fibrobroncospia y broncografía que demuestran una estenosis acentuada en el bronquio izquierdo a $1 \mathrm{~cm}$. de la carina. Figura 1.

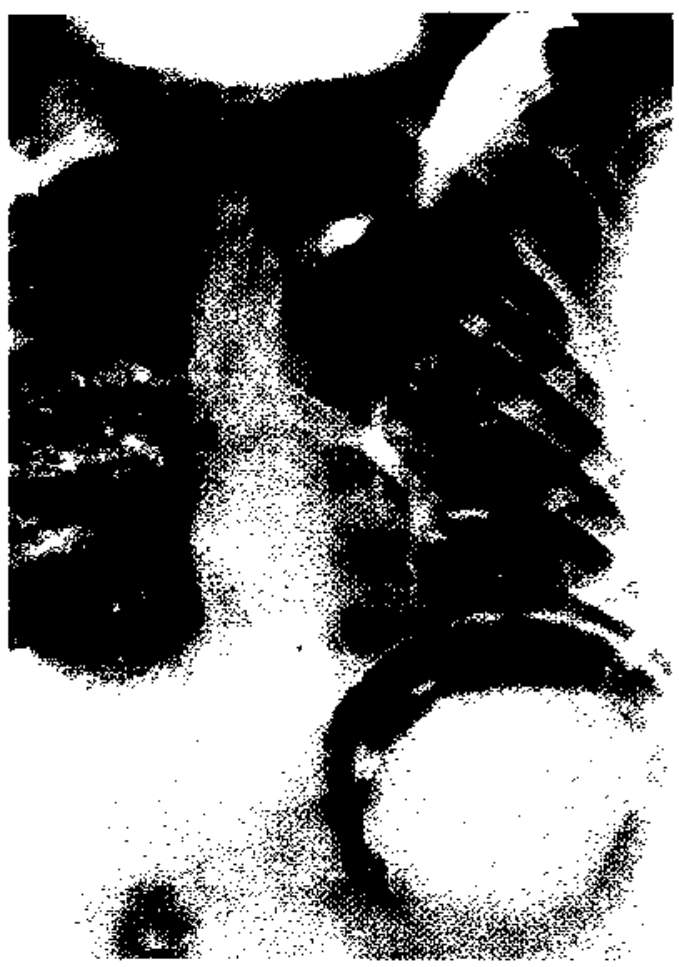

Figura 1.

Es intervenida en Agosto de 1978, bajo anestesia general con intubación selectiva del bronquio derecho, se practica toracotomía izquierda; el 
abordaje bronquial se realiza separando hacia arriba la arteria pulmonar izquierda, disecada extensamente. El nervio vago es desplazado hacia atrás. Se reseca alrededor de $1 \mathrm{~cm}$. de bronquio y se reimplanta el bronquio en la carina con 5 puntos de separados Tycron 3-0. El post operatorio transcurrió sin complicaciones y se da de alta 10 dias después de la intervención.

El estudio histopatológico de la pieza mostró fibrosis sub-epitelial, hiperplasia de la musculatura lisa, escaso exudado inflamatorio linfocitario sub-epitelial; el cartilago es de aspecto normal levemente celulat e involucra casi toda la circuns. ferencia bronquial ya que la zona membranosa es muy pequeña.

El último control broncográfico 30 meses después de la intervención muestra un satisfactorio diámetro y crecimiento de la zona de sutura. Figura 2.

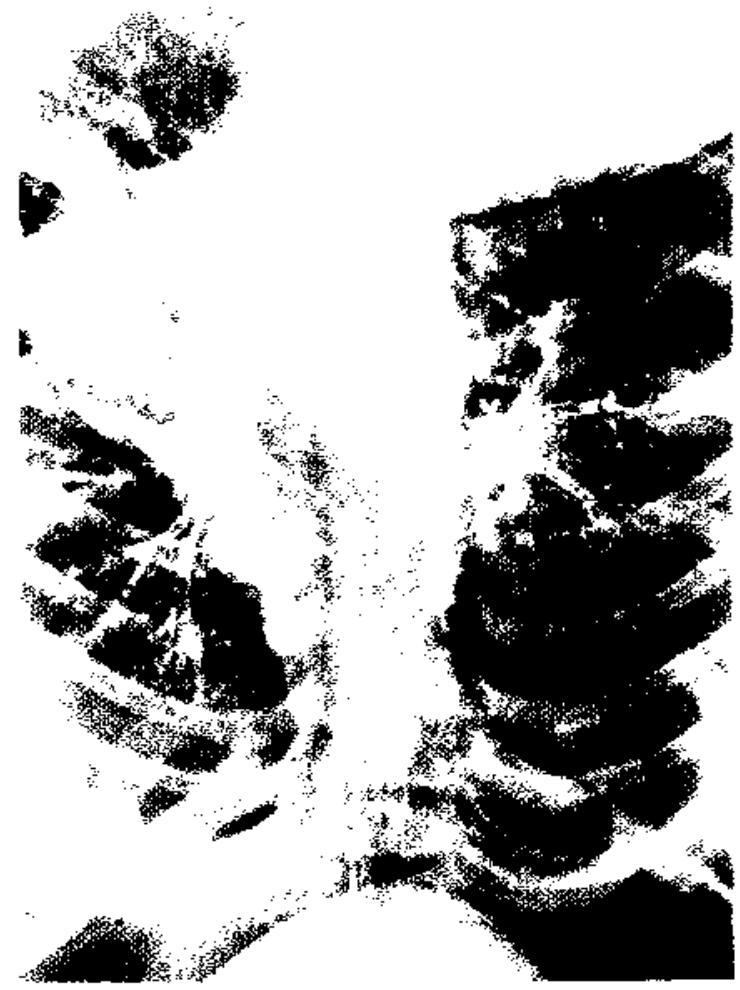

Figura 2.

\section{DISCUSION}

La estenosis bronquial en el niño debida a cuerpo extraño y broncospía es un cuadro patológico sumamente raro; no hemos encontrado ninguno descrito en la literatura.

Los mecanismos que causaron la estenosis pueden atribuirse a la permanencia de un cuerpo extraño que, tratándose de un poroto, en la humedad aumenta de diámetro con mucha facilidad, creando asi las mismas condiciones que el bałón de un tubo endotraqueal, produciendo isquemia e infección de la pared bronquial que lleva a la necrosis tisular y luego la cicatrización este. nótica. El origen congénito puede ser descartado ya que en la broncospía realizada para extraer el cuerpo extraño no se observó estenosis del bronquio, hecho que fue observado 11 meses más tarde al repetir la endoscopía.

Es importante destacar además que en este caso, el procedimiento broncoscópico fue difícil, extrayéndose el cuerpo extrafto sólo después de cortarlo en varios trozos, lo que demuestra su grado de impactación y hace suponer daño de la pared bronquial con la pinza de biopsia durante el procedimiento.

Técnicamente el abordaje por debajo de la arteria pulmonar es sencillo en el niño, ya que los tejidos laxos hacen fácil el abordaje de la carina. A su vez, una vez realizada la sutura, esta se encuentra rodeada y verdaderamente aprisionada por las estructuras vecinas, lo que permite un cierre hermético a pesar que la sutura término terminal se realizó sólo con 5 puntos de sutura (Tycron $3-0$ ).

\section{RESUMEN}

Se presenta el caso de una nifra de 5 años portadora de una estenosis en el bronquio izquierdo a un centímetro de la carina secundaria a la impactación de un cuerpo extraño (poroto). Se describe la técnica quirúrgica de su reparación y el buen resultado 30 meses más tarde.

\section{REFERENCIAS}

De Ritis G., Rillini G., Rosctoni G., Sani A.: Le Stenosis Branchiali. Policlínico Sez. Med. 83, 29-45, 1976. 